\title{
Pain Scale for Plantar Fasciitis
}

\author{
by Buck Willis, $\mathrm{PhD}^{1} \rrbracket$, Angel Lopez, $\mathrm{DPM}^{2}$, Andres Perez, MD-DPM ${ }^{3}$, Larry Sheridan, DPM${ }^{4}$, \\ Stanley R Kalish, DPM ${ }^{5}$
}

The Foot and Ankle Online Journal 2 (5): 3

Background: Plantar fasciitis (PF) is a common and debilitating pathology whose chief complaint is acute plantar heel pain. This pathology affects between 1 and 2 million Americans each year, but a specific descriptive pain/disability scale has not been available to measure the severity and/or changes in pain specific to this pathology. The purpose of this study was to examine the PF, Pain and Disability Scale (PFPS) and its ability to discriminate between pain from PF and other heel pain.

Methods: The PFPS survey includes a series of key questions that relate to symptoms and control questions for PF. It also includes visual analogue scale and questions to measure the effect the pain has on activities of daily living. This questionnaire was administered to 400 patients who had been diagnosed with either PF or another pathology causing heel pain (e.g. calcaneal bursitis). Patients' mean age was 50 years \pm 16 (242 females and 158 males).

Results: There was a significant difference in scores from PF patients versus other heel pain patients when compared in a one-way analysis of variance $(P<0.0001)$. Post-hoc t-tests did not show a difference between genders $(P>0.05)$ or ethnicity $(P>0.05)$.

Discussion: The survey was effective in measuring pain that is unique to PF through questions of mobility/function and activities of daily living, and it showed a significant difference between patients with other heel pain vs. PF. This could become an effective tool in diagnosis and assessment of pain unique to PF.

Key words: Plantar fasciitis, Pain and disability scale, heel pain

$\mathrm{P}$ lantar fasciitis $(\mathrm{PF})$ is considered to be one of the most common foot pathologies affecting 1 to 2 million Americans each year. ${ }^{7,9-11}$ However, a descriptive pain/disability scale has not been available to measure severity and/or changes in pain specific to this pathology.

\footnotetext{
Address correspondence to: Texas State University, Health Physical Education and Recreation, San Marcos, TX (at the time of this study) Email: BuckPhD@yahoo.com

${ }^{1}$ Dynasplint Systems, Inc. PO Box 92135 Austin, TX 78709. (512) 297-1833

${ }^{2}$ Lopez Podiatry; Ft Worth, Texas 910 W North Side Dr Ft Worth, TX

76164. (817) 625-1103 .Dralldpm@aol.com

${ }^{3}$ Orlando Foot and Ankle Clinic; Orlando, FL 3670 Maguire Boulevard, Suite 220 Orlando, FL 32803. (407) 423-1234 AnPerez63@hotmail.com

${ }^{4}$ Kaiser Permanente, Musculoskeletal Services; Sacramento, CA 2025

Morse Avenue Sacramento, CA 95825. (916) 973-5899

larry.sheridan@kp.org

${ }^{5}$ Atlanta Foot and Leg Clinic; Jonesboro, GA 6911 Tara Boulevard, Suite

\#104 Jonesboro, GA 30236 (770) 477-9535 Srkalish@bellsouth.net
}

Current orthopaedic pain scales include a simple 10 point Visual Analogue Scale (VAS) ${ }^{7,18}$ to the "Disabilities of Arm/Shoulder/Hand" and the "LevineKatz. Functional Survey," which measure the effect and disabilities of upper extremity pain has during Activities of Daily Living (ADL).

An overall foot-health questionnaire has been developed, ${ }^{1}$ but this survey measures the broad health status of one's foot and would not show specific changes in pain from PF in accordance to ADLs. The VAS scores pain on a scale of 1 to 10 or 1 to 100 and has been effective in helping clinician's measure pain. However, confounding variables affect these scores. 
Differences in VAS scores between different dates may not be true barometer of the change in pain. The foot health status questionnaire ${ }^{7,8}$ and the VAS $2,7,8,13,17,18$ have been used in many studies, but other authors have searched for a better method to measure changes following treatment of PF. Rose, et al., examined this question using nerve conduction (medial calcaneal nerve and the posterior nerve) to gain further insight into patient's true recovery from PF. ${ }^{15}$

The foot function index $(\mathrm{FFI})^{2,8}$ was compared in clinical settings with PF patients by Landorf and Radford. ${ }^{8}$ Patients were recruited for two trials to examine the "minimal important difference" for the patients when comparing these pain scales. The results indicated the difference that would benefit clinician's interpretation, but Landorf and Radford remarked that these pain scores themselves do not "Take into account the affect a disorder has on the patient's life in general. ${ }^{\text {, }}$

\section{Effective Orthopaedic Rehab: Seven Steps to Complete Recovery} was written as a supplemental book for athletic training students and measures pain in ADLs and the effect motion and movement may have on the pain. Reviewers of this scale felt that it was a more complete, analytical measurement of pain than would be acquired by a VAS. ${ }^{19}$

The validity and source of the questions used in this PF, Pain and Disability Scale (PFPS) survey came from examination and comparison to questions in other text books, recent manuscripts, and from the clinical practice of diagnosing and treating PF., ${ }^{1,3,8,11,17-}$

19 The PFPS has been compared and validated beside the foot function index, and the 100 point VAS is actually included in the PFPS. However, the PFPS gives a more detailed, analytical analysis of patients' pain by also examining symptomatic questions used in the differential diagnosis and questions regarding pain in ADLs. The purpose of this study was to examine the PFPS survey's ability to discriminate between pain from PF and other heel pain.

\section{Methods}

Four hundred patients who presented with acute heel pain were recruited at four different foot/ankle clinics. Each patient was clinically examined to diagnose and categorize PF versus another heel pain condition such as calcaneal bursitis or calcaneal fractures. (See differential diagnosis on Table 1 and demographics of the patients can be seen in Table 2.) All patients completed the PFPS and informed consent was obtained for each patient participating in this study. Ethical approval for this study was granted by the Copernicus Group IRB.

The PFPS includes unique symptomatic questions in differentiating PF and control questions as well, which make scores of 0 or 100 points to be invalid. If a patient had recorded either of these scores the test would have been deleted from this study, but no such incidence occurred. The PFPS questions were internally validated with inclusion of the 100 point VAS and externally validated through orthopaedic text and podiatric publications. ${ }^{1,6,8,16,18,19}$

\section{Data Analysis}

After PFPS questionnaires were collected from patients at four foot/ankle clinics (This form is blinded to the patent's name and only the Date of Birth was used for tracking as required under the Declaration of Helsinki). A one-way analysis of variance (ANOVA) with post-hoc t-tests were used to determine differences between gender or ethnicity. All statistical tests were performed at an alpha level of 0.05 using SPSS and Microsoft Excel software.

\section{Results}

There was a statistically significant difference in scores of PF patients vs. scores of other heel pain patients $(\mathrm{P}<0.0001, \mathrm{t}=23.78, \mathrm{n}=400, d f=398$, sed $=1.487$ ) (see Table 3 ). There was not a statistically significant difference between genders $(\mathrm{P}>0.05)$ or ethnicities ( $\mathrm{P}>0.05)$. 


\begin{tabular}{|l|}
\hline Abductor digiti quintri nerve entrapment \\
\hline Ankylosing spondylitis \\
\hline Bone bruise \\
\hline Calcaneal epiphysitis \\
\hline Calcaneal stress fracture \\
\hline Fat-pad atrophy \\
\hline Heel contusion \\
\hline Inflammatory arthropathies \\
\hline Neuropathic pain \\
\hline Paget disease \\
\hline Psoriatic arthritis \\
\hline Reiter syndrome \\
\hline S1 radiculopathy \\
\hline Sickle cell disease \\
\hline Spondyloarthropathy \\
\hline
\end{tabular}

Table 1 Differential diagnosis in PF.

The mean difference between PF vs. other heel pain was more than 35 points and this is believed attributed to the fact that the PFPS includes questions uniquely symptomatic to PF like pain from the first steps in the morning and reduced morning pain from toe walking. (See Figure 1, study questionnaire.) The purpose of this study was to examine the PFPS survey's ability to discriminate between pain from plantar fasciitis (PF) and other heel pain.

\section{Discussion}

Current studies support the need for a pain scale that can uniquely assess pain exclusive to PF for diagnosis and assessment. ${ }^{2,6,8,11,15,18}$ Landorf and Radford question the statistical significance in changes with the VAS because of the multiple confounding variables associated with that test. They determined that a "Minimally Important Difference" was based not on statistical values alone but changes in "the effect a disorder has on the patient's life in general".

\begin{tabular}{|l|}
\hline$n=400$ \\
\hline Mean Age $50.9( \pm 16.5)$ \\
\hline Female $60 \%$, Male $40 \%$ \\
\hline Ethnicity (Asian 6\%, Black 16\%, \\
\hline Caucasian 40\%, Hispanic 36\% \\
\hline Other $2 \%$ ) \\
\hline
\end{tabular}

Table 2 Patient demographics.

\begin{tabular}{|lcc|}
\hline Patients & Plantar Fasciitis & Other Heel Pain \\
\hline$n=400$ & 201 & 199 \\
\hline Mean Score: & 67.3 & 31.5 \\
\hline SD: & 12.7 & 16.4 \\
\hline Score Range: & $(23-94)$ & $(8-80)$ \\
\hline
\end{tabular}

Table 3 Results (SD = standard deviation)

Bennett, et al., developed a questionnaire to measure overall foot health. ${ }^{1}$ Their questionnaire examined four different domains of questions (with 107 participants). The "domains" (or categories) of questions were Pain, Function, Footwear, and General Foot Health. One functional question was "How much does your foot health limit you in walking" which is ideal in measuring the overall foot health but is not symptom specific to PF.

Rose, et al., ${ }^{15}$ suggest using nerve conduction to evaluate changes in PF but few podiatrists may have nerve conduction equipment in their office. The PFPS can be administered in almost any setting. The existing pain scales are effective in gauging overall pain, ${ }^{1,2,8,13,17,18}$ but they lack the specific inclusion of symptomatic questions that will allow specific, objective, analytical measurement of change in symptoms unique to PF. The PFPS effectively showed the difference between PF patients vs. patients with other pathologies causing heel pain.

The PFPS will allow clinician's more descriptive, exclusive analysis of PF pain for evaluation of treatment than the 100-pint VAS scale. 
For example a young woman's score VAS and PFPS drops from 70 to 60 which would be "statistically significant" but, it may not show "Minimally Important Difference". However a comparison the current vs. previous PFPS tests of this patient, shows a changed Q\#14 because she no longer prefers toe walking, and Q\#15 which shows reduced pain from "Walking in the morning" and reduced pain from "Standing after watching a movie." This would display a "Minimally Important Difference" and answer the need for a pain scale that can uniquely assess pain exclusive to PF for diagnosis and evaluation. ${ }^{2,6,8,11,15,18}$

In this study the PFPS has effectively discriminated pain unique to PF patients vs. heel pain caused by other foot pathologies. A future study should be conducted using this PFPS to measure changes in PF patients' pain through a treatment regime, lasting several months. That would further validate the efficacy of this questionnaire in diagnosis and assessing pain unique to $\mathrm{PF}$.

\section{References}

1. Bennett PJ, Patterson C, Wearing S, Baglioni T. Development and validation of a questionnaire designed to measure foothealth status. J Am Podiatr Med Assoc 88 (9):419 - 28, 1998.

2. Digiovanni BF, Nawoczenski DA, Malay DP, Graci PA, Williams TT, Wilding GE, Baumhauer JF. Plantar fascia-specific stretching exercise improves outcomes in patients with chronic plantar fasciitis. A prospective clinical trial with two-year followup. J Bone Joint Surg 88A:1775 - 81, 2006.

3. Dmitri Luke BS. Plantar fasciitis: a new experimental approach to treatment. Med Hypotheses 59(1): 95 - 7, 2002.

4. Fishco WD, Goecker RM, Schwartz RI. The instep plantar fasciotomy for chronic plantar fasciitis. A retrospective review $J$ Am Podiatr Med Assoc 90 (2): 66 - 69, 2000.

5. Guldemond NA, Leffers P, Sanders AP, Emmen H, Schaper NC, Walenkamp GH. Casting methods and plantar pressure: effects of custom-made foot orthoses on dynamic plantar pressure distribution. J Am Podiatr Med Assoc 96 (1): 9 - 18, 2006.

6. Intenzo CM, Wapner KL, Park CH, Kim SM. Evaluation of plantar fasciitis by three-phase bone scintigraphy. Clin Nucl Med $16(5): 325-8,1991$.
7. Landorf KB, Keenan AM, Herbert RD. Effectiveness of foot orthoses to treat plantar fasciitis: a randomized trial. Arch Intern Med. 166 (12):1305 - 10, 2006.

8. Landorf KB, Radford JA. Minimal important difference: values for the foot health status Questionnaire, Foot Function Index and Visual Analogue Scale. The Foot 18(1):15-19, 2008.

9. Lemont H, Ammirati KM, Usen N. Plantar fasciitis: A degenerative process (fasciosis) without inflammation. $J \mathrm{Am}$ Podiatr Med Assoc 93 (3): 234 - 237, 2003.

10. Martin JE, Hosch JC, Goforth WP, Murff RT, Lynch DM, and Odom RD. Mechanical treatment of plantar fasciitis: A prospective study. J Am Podiatr Med Assoc 91(1): 55 - 62, 2001.

11. Marx, RC, Mizel, MS. What's new in foot and ankle surgery. J Bone Joint Surg 90A: 928 - 942, 2008.

12. $\mathrm{Ng} \mathrm{A}$, Beegle T, Rockett AK. Atypical presentation of plantar fasciitis secondary to soft-tissue mass infiltration. $\mathrm{J} \mathrm{Am}$ Podiatr Med Assoc 91 (2): 89 - 92, 2001.

13. Radford JA, Landorf KB, Buchbinder R, Cook C. Effectiveness of calf muscle stretching for the short-term treatment of plantar heel pain: a randomised trial. $B M C$ Musculoskeletal Disord 19: 8: 36, 2007.

14. Riddle DL, Pulisic M, Pidcoe P, Johnson RE. Risk factors for Plantar fasciitis: a matched case-control study. J Bone Joint Surg Am. 2003 May;85-A(5):872-7. Erratum in: J Bone Joint Surg 85A (7):1338, 2003

15. Rose JD, Malay DS, Sorrento DL: Neurosensory testing of the medial calcaneal and medial plantar nerves in patients with plantar heel pain. J Foot Ankle Surg 42 (4):173 - 7, 2003.

16. Ross M. Use of the tissue stress model as a paradigm for developing an examination and management plan for a patient with plantar fasciitis. J Am Podiatr Med Assoc 92(9): $499-$ 506, 2002.

17. Schepers T, Heetveld MJ, Mulder PG, Patka P. Clinical outcome scoring of intra-articular calcaneal fractures. J Foot Ankle Surg 47 (3): 213 - 8, 2008.

18. Walther M, Radke S, Kirschner S, Ettl V, Goblke F. Power doppler findings in plantar fasciitis. Ultrasound Med Biol 30(4): 435 $-40,2004$.

19. Willis B. Effective orthopedic rehab: Seven steps to complete recovery, Chapter I, 10 - 15, Trafford publishing, Victoria BC, Canada, 2003. 


\section{PFPS Plantar Fasciitis Pain/Disability Scale}

$\begin{array}{lll}\text { MALE or FEMALE } & \text { Dx: } & \text { Today's date _ } \\ \text { Date of Birth } & \text { Ethnicity__ } & \text { Onset of pain }\end{array}$

1. VAS: Rate your pain on a scale of 1 to 100. $\div 8.3=$ score of

2. How many days a week does pain affect your mobility? (1-7)

3. Is the pain on the surface or deep? _ Surface $=1$, Deep $=3$

\section{Pain Description}

4. Where is your pain located? $0=$ Toes, $1=$ Ball of foot, $2=$ Mid sole, $3=$ Bottom of Heel

5. In the past 6 weeks how often have you had pain?

$$
0=\text { Every other week } 1 \text { = Once a week } 2 \text { = Once a day } 3=\text { Many times a day }
$$

6. How often since the onset of pain, have you been pain free?

$$
0 \text { = weeks, } 1 \text { = days, } 2 \text { = hours, } 3=\text { minutes }
$$

7. How long does the pain last?

$0=$ only when I over exert, 1 = pain lasts for less than one hour, 2 = pain lasts for one to two hours, $3=$ pain lasts for more than two hours

8. In the past 6 weeks what time of day is your pain the worst? (Note this specifically for diagnosis of different problems).

0 = Always the same, $1=$ Only in the afternoon, 2 = Both day \& night,

3 = Only when you first get up

9. In the past 6 weeks does the pain make it hard to get to sleep?

$0=$ Never, 1 = Some nights, 2 = most nights, 3 = every night

10. In the past 6 weeks, how often does your pain awaken you?

$0=$ Never, 1 = Some nights, 2 = most nights, 3 = every night

11. How difficult is it to cope with your pain?

$0=$ Easy to deal with, $1=$ Inconvenient, $2=$ Troublesome, $3=$ Almost impossible

12. How much does the pain interfere with your athletics or with weight-bearing activities such as walking?

$$
0 \text { = never, } 1 \text { = occasionally, } 2 \text { = frequently, } 3 \text { = always }
$$




\section{Mobility/Function}

13. When you awake, how many minutes must elapse before you can walk comfortably?

$0=$ No time, 1 = less than 10 minutes, $2=11$ to 30 minutes, $3=$ it takes over 30 minutes until I can walk comfortably

14. Is it more comfortable to walk on your toes than walk flat footed?

$$
0=\text { No, } 3=\text { Yes }
$$

15. Please check the columns below that describe how much your pain affects you in different conditions. (If you are unable to perform such a task list check "Severe."

\begin{tabular}{|l|l|l|l|l|}
\hline Activity & $0=$ Not at all & $1=$ Very little & $2=$ Moderate & $3=$ Severe \\
\hline $\begin{array}{l}\text { Walking in the } \\
\text { morning }\end{array}$ & & & & \\
\hline $\begin{array}{l}\text { Standing up on } \\
\text { your toes }\end{array}$ & & & & \\
\hline Driving & & & & \\
\hline Climbing Stairs & & & & \\
\hline Descending Stairs & & & & \\
\hline Reaching up & & & & \\
\hline Bending over & & & & \\
\hline Walking bare foot & & & & \\
\hline $\begin{array}{l}\text { Standing after } \\
\text { watching a movie }\end{array}$ & & & & \\
\hline Riding a bike & & & & \\
\hline $\begin{array}{l}\text { Running a short } \\
\text { distance }\end{array}$ & & & & \\
\hline
\end{tabular}

16. How often do you take medication for your pain?

$0=$ Less than once a week, 1 = Several times per week, 2 = Once Daily, $3=$ More than once every day, since the injury

17. Describe the medications' affect on your pain.

$0=$ It always stops the pain, $1=$ Decreases the pain, $2=$ Usually takes the pain away, 3 = Little or no affect on the pain

18. How does the pain affect you emotionally?

$0=$ No affect, $1=$ It causes anxiety, 2 = The pain worries me daily, $3=$ It makes me consider giving up my recreational activities

19. Rate the limitations that your pain/injury affects your daily life style.

0 = Does not limit your lifestyle, 1 = some activities avoided (i.e. riding in car or sitting in stadium for hours), 3 = You avoid all activity due to injury

Total Score Date

Adapted format from: Effective Orthopedic Rehab: Seven Steps to Complete Recovery. ISBN \#141200522-1

(C) Copyright Dynasplint Systems, Inc., 2008 